\section{Research mentors sought}

ACRL's Research Committee seeks experienced researchers willing to share their skills in a mentoring relationship. The committee is sponsoring a mentoring program for those librarians who aspire to conduct research but need to develop their skills. The program supports goal one of ACRL's new Strategic Plan, "to contribute to the total professional development of academic and research librarians.

For details on becoming or obtaining a mentor contact Marilyn J. Martin, Chair, ACRL Research Committee, Rowan College Library, 201 Mullica Hill Rd., Glassboro, NJ 08028-1701; phone (609) 256-4981; e-mail: martin@library. rowan.edu

\section{ACRL publishes calendar feafuring C\&RL News covers}

ACRL has featured some of its most popular covers from CERL News in a limited edition 17-month academic appointment calendar. This spiralbound, monthly calendar, which highlights important ACRL dates and events, runs from August 1996 through December 1997 and

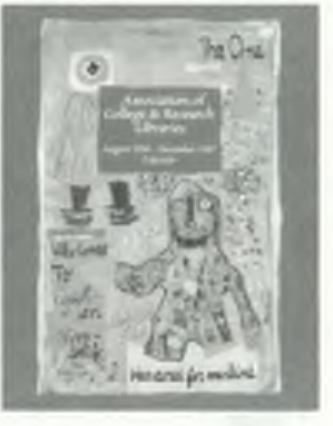
will be available for $\$ 7.00$ at the ALA stores at the 1996 Annual Conference and 1997 Midwinter Meeting. Not attending the conference? Copies of the calendar are available by mail for $\$ 9.00$, which includes shipping and handling. To receive a copy send your check, made payable to ACRL, to: ACRL Calendars, 50 E. Huron St., Chicago, IL 60611.

\title{
The paper albatross
}

Ed. note: Alsbough claims are often made about the paperless sociery, in reality I find that e-mail and the ease of pbotocopying and printing things out from my computer bave increased the amonint of paper I live with. I thonght readers would find this piece of interest. (Reprinted with permission from The University of Memphis Libraries News, spring 1996, vol.2. no.1.)

When we had the card catalog and relied exclusively upon printed indexes, we provided "P" slips for people to write down call numbers and citations. Today the card cata$\log$ and many of the printed indexes are online, and our patrons use reams of paper and print citations, call numbers, and even full texts of articles. Instead of ordering boxes of "P" slips, we order truckloads of paper. In FY94/95 we used 94 cases (940 reams) of paper. During this fiscal year, we project that we will use 150 cases (1,500 reams). At $\$ 3.00-\$ 5.00$ a ream, we will spend from $\$ 4,500$ to $\$ 7,500$ just for paper. Printing also requires printer maintenance and a large supply of toner. At $\$ 90$ per cartridge, we will spend about $\$ 1,800$ this year for toner. We spend a lot of staff time loading paper and troubleshooting.

Much of what is printed is used by students and faculty for their research, but too much is wasted. Unfortunately, printing through the libraries' system is complicated and counterintuitive. There are at least five different print functions to learn, each pecu- liar to a specific database or system. Because one printer services several computers, print cotnmands go into a printer queue. Users who don't understand this print sequence inadvertently print multiple copies. Library staff have found 21 copies of a single printout, none of which were picked up. Other users print one citation (two lines) per page. Because of the networked situation, each printout has a separate cover page, which is also wasted paper. In order to cut waste, we use both sides of the paper. That means that we have to gather and sort the paper. When both sides are used, we dump it in the recycle bin. Of course, all of this paper shuffling wastes staff time, too.

Printing costs may be justified when printing is used in support of the academic curriculum and research. Not everything needs to be printed, however. Sometimes a "P" slip will still do to jot down a call number or a citation. The library staff asks that users carefully evaluate resources before printing, and help us conserve paper, money, and trees. Betsy Park, bead. Reference Department, Uni versity of Memphis Libraries 